\title{
A simple flow switching interface for two-dimensional capillary supercritical fluid chromatography
}

\author{
S. Hishimoto and Y. Hirata \\ School of Materials Science, Toyohashi University of Technology, Toyohashi 441-8580, Japan
}

\begin{abstract}
A simple flow switching interface was developed for two-dimensional capillary supercritical fluid chromatography. The interface consisted of a three-way valve and three fused silica capillaries. A novel connection method to minimize dead volume and to eliminate unswept space in the system was also developed. With the system heart-cutting is easy to perform and the selectivity for the separations on the secondary column can be tuned simply by changing the resistance of connection capillary between two columns. The effectiveness of this system was demonstrated by the separations of isomeric ethoxylate oligomers and fatty acid cholesteryl esters.
\end{abstract}

upercritical fluid chromatography (SFC) has been recognized as a powerful separation technique supplementing gas (GC) and liquid chromatography (LC). Although capillary SFC has a high resolving power, the efficiency of a single capillary column is still inadequate for the separation of closely related compounds and complex mixtures such as isomeric compounds and environmental and biological samples. Multi-dimensional chromatography is an excellent technique for obtaining increased resolving power. Although various forms of multi-dimensional (mostly twodimensional) chromatography using GC, LC and SFC have been reported and some of them are well established as reviewed [1,2], a limited number of reports have been published with respect to capillary SFC-SFC $[3,4]$.

In this study, we developed a simple flow switching interface for two-dimensional capillary SFC. A novel plumbing method to construct the system was also developed. The primary column was a non-polar methyl polysiloxane column and the secondary column a polar polyethylene glycol column. This geometry was more effective for controlling the resolutions on the secondary column than the reversed one. Pressure and temperature affected the selectivity on the secondary column as in single column SFC.

\section{Experimental}

\section{Chemicals}

A mixture of paraffins $\left(\mathrm{C}_{18}-\mathrm{C}_{26}\right)$, fatty acid methyl esters $\left(\mathrm{C}_{16} \mathrm{Me}-\mathrm{C}_{22} \mathrm{Me}\right)$ and alcohols $\left(\mathrm{C}_{12} \mathrm{OH}-\mathrm{C}_{18} \mathrm{OH}\right)$ (Tokyo Kasei,
Tokyo, Japan) with even carbon atoms was used for fundamental study on two-dimensional SFC as a test sample. Cholesterol (chol) and its fatty acid derivatives, laurate (chol-12:0), myristate (chol-14:0), palmitate (chol-16:0), palmitoleate (chol-16:1), stearate (chol-18:0), oleate (chol18:1), linoleate (chol-18:2), linolenate (chol-18:3) and arachidonate (chol-20:4), were purchased from Sigma (St. Louis, MO, USA). Oligomeric sample with two branches of polyoxyethylene (2,4,7,9-tetramethyl-4,7bis(polyoxyethylene)-5-decyne) was obtained from Hayashi Kasei (Nagoya, Japan). All these samples were dissolved in dichloromethane. Ultra high purity carbon dioxide (ShowaTansan, Yokkaichi, Japan) was used as mobile phase.

\section{Instruments}

The pump was an LC-6A liquid chromatograph pump (Shimadzu, Kyoto, Japan) equipped with a pump head cooler (MC-28T, Netsudenshi Kogyo, Tokyo, Japan) and a home-made pressure programmer. The supercritical fluid chromatograph was a HP 5840A gas chromatograph (Hewlett-Packard, Avondale, Penn., USA) with dual flame ionization detectors (FID). The FID temperature was held at 300 or $350{ }^{\circ} \mathrm{C}$. Capillary columns were HP-1 (100 $\mu \mathrm{m}$ i.d. $\times 10 \mathrm{~m}, 0.40 \mu \mathrm{m}$ film thickness $)$ and HP-WAX $(100 \mu \mathrm{m}$ i.d. $\times 10 \mathrm{~m}, 0.20 \mu \mathrm{m}$ film thickness). In most cases, the former was used as a primary column and the latter as a secondary column in two-dimensional SFC. The column temperature was between 80 and $120^{\circ} \mathrm{C}$. Samples were injected with a Rheodyne 7520 injector (Cotati, CA, USA) with a $0.2 \mu \mathrm{L}$ rotor. The column pressure was programmed at a rate of $5 \mathrm{~atm} / \mathrm{min}$ after a $10 \mathrm{~min}$ isobaric period at $100 \mathrm{~atm}$. Data were collected with a Shimadzu C-R4A integrator. Restrictors for FID were integral type, which were prepared from a $30 \mu \mathrm{m}$ i.d. fused silica capillary. The end of the restrictor was closed in a oxygen-hydrogen flame and scrubbed with a \#1500 sand paper so as to give a flow rate of $1.0-1.2 \mathrm{~mL} / \mathrm{min}$ for nitrogen gas at $25 \mathrm{~atm}$, which results in a $3-4 \mathrm{~cm} / \mathrm{s}$ mobile phase flow rate.

\section{Interface for two-dimensional capillary SFC}

The two-dimensional capillary SFC system developed in this study is shown in figure 1 . The interface comprised a bypass valve (\#2, Rheodyne 6030) and three fused silica capillaries (\#6-\#8). The transfer line (\#6) was a $10 \mu \mathrm{m}$ i.d. $\times 10-20 \mathrm{~cm}$ fused silica capillary, and two bypass lines (\#7 and \#8) were a $50 \mu \mathrm{m}$ i.d. $\times 20 \mathrm{~cm}$ fused silica capillary. Detailed structure of the connections in one of butt connectors (DKK, Tokyo, Japan) in the interface is shown together. Two stainless steel tubings $(0.1 \mathrm{~mm}$ i.d., $0.3 \mathrm{~mm}$ o.d., GL Science, Tokyo, Japan) were welded with silver 
solder into a stainless tubing $(0.7 \mathrm{~mm}$ i.d., $1.06 \mathrm{~mm}$ o.d., Nilaco, Tokyo, Japan). These lines were connected to the primary column (\#4), the restrictor for FID 1 (\#9), the transfer line (\#6), and the bypass line 1 (\#7) using butt connectors (not shown). This method minimized dead volume and eliminated unswept space. Butt connectors were also used to connect the primary column and the interface lines to the injector and the bypass valve, respectively, via a $0.1 \mathrm{~mm}$ i.d. stainless steel tubing, of which one end was welded with silver solder into a stainless steel tubing $(0.5 \mathrm{~mm}$ i.d., $1 / 16$ in o.d.) to connect to a standard $1 / 16$ in port of the valves.

\section{Principle and procedures for heart-cutting}

In this two-dimensional SFC system, the flow rate and the flow direction are dependent on the resistances of transfer line (\#6), bypass lines (\#7 and \#8), and FID restrictors (\#9 and \#10) and on the position of the bypass valve (\#2). The bypass valve is either switched to one of bypass lines or closed (i.e., switched to an intermediate position to stop flow through the bypass lines): note that three valve positions are employed. The plumbing in this system can be regarded as an electric circuit shown in figure 2, where the bypass valve is switched to the bypass line 2 . The pressure and the flow rate correspond to voltage and electric current, respectively. Analysis of the circuit resulted in following general requirements for this system. FID restrictors should have the highest resistance. Transfer line should have higher resistance than column, and two bypass lines should have lower resistance than column. Figure 3 shows estimated pressures at the outlet of primary column and at the inlet of secondary column for a typical combination of resistances, where relative pressures to the pump pressure are plotted for three valve positions.

Typical operations for the separation and heart-cutting are as follows. When the bypass valve (\#2) is switched to the bypass line 2 (\#8), the mobile phase in the transfer line flows in the direction indicated by the arrow with the dotted line in figure 1 and exits from the restrictor 1 (\#9) together with the flow from the primary column. At this time, samples are injected and the pressure programming is started after an appropriate isobaric period. In this conditions, therefore, all the components from the primary column are detected by FID 1. When the components of interest starts to emerge from the primary column, the bypass valve (\#2) is closed. Then, the mobile phase flows through the transfer line in the direction indicated by the arrow with the solid line in figure 1 . This allows to transfer the components from the primary column to the secondary column. The pump pressure at this time $\left(P_{\text {ref }}\right)$ is referred to in the next cycle. After an appropriate period for transferring solutes, the injector (\#3) is closed. The solutes transferred into the secondary column are separated with either of two methods as follows. In the first method (method-I) where the bypass valve (\#2) is switched to the bypass line 1 (\#7), the mobile phase is supplied into the secondary column through both the bypass line $1(\# 7)$ and the transfer line (\#6). In the second method (method-II) where the bypass valve (\#2) is switched to the bypass line 2 (\#8), the mobile phase is supplied through the bypass line 2 (\#8). Pressure is being programmed during these operations. After the separation on the secondary column ends, the pump pressure is lowered slowly down to $P_{\text {ref }}$. Then, the injector is opened and the

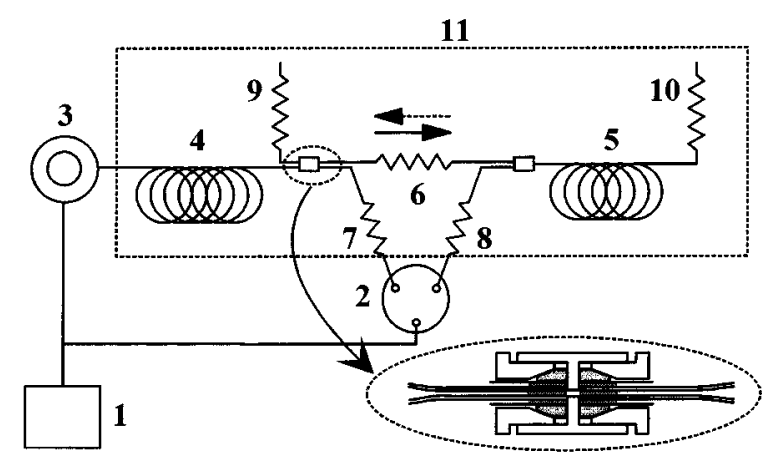

Figure 1. Schematic diagram of two-dimensional SFC system. 1 =pump, 2 =bypass valve, $3=$ =injector, $4=$ column $1,5=$ column 2 , 6=transfer line, 7=bypass line 1, 8=bypass line 2, 9=restrictor for FID 1, 10=restrictor for FID 2, 11=oven. Detailed descriptions in experimental.

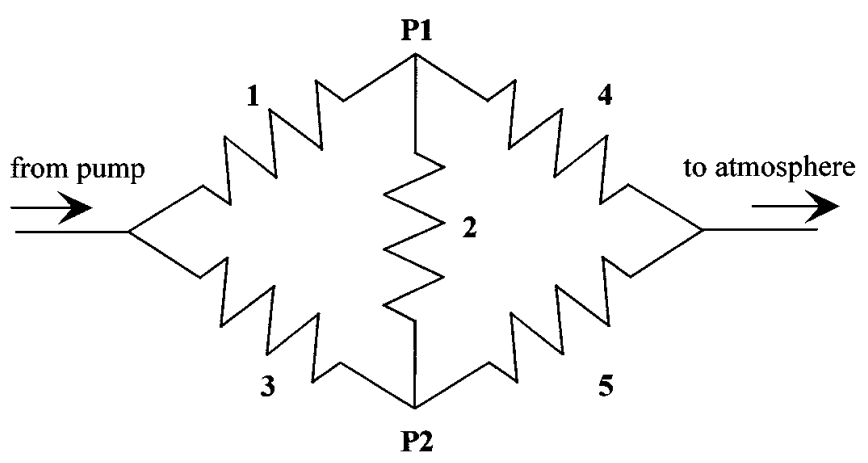

Figure 2. Electric circuit corresponding to two-dimensional SFC system when the bypass valve is switched to the bypass line 2. 1=column 1, 2=transfer line, 3=bypass line 2, 4=restrictor for FID 1, 5=column 2 + restrictor for FID 2. P1 and P2 are pressures at the outlet of column 1 and at the inlet of column 2 , respectively.

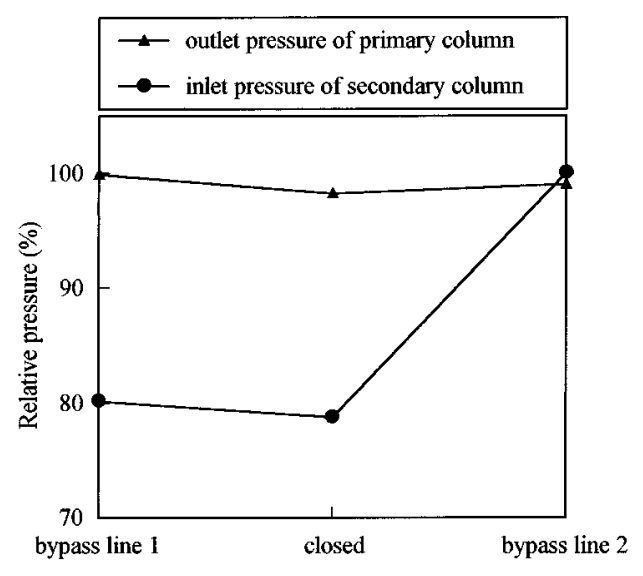

Position of bypass valve

Figure 3. Estimated pressures at the outlet of the primary column and at the inlet of the secondary column for bypass valve positions. Resistance: 1000 (FID restrictor 1 and 2), 250 (transfer line), 10 (column 1 and 2), 2 (bypass line 1 and 2). Injector is closed for "bypass line 1 ", and open for "closed" and “bypass line 2". 
separation of the solutes remained in the primary column is restarted.

\section{Results and discussion}

\section{Operation modes of two-dimensional SFC system}

In most cases HP-1 and HP-WAX column were used as a primary and secondary column, respectively, although reversed geometry was also tested. Since the stationary phase of HP-1 (100\% dimethyl polysiloxane) is nonpolar and the stationary phase of HP-WXA (polyethylene glycol, PEG) is polar, the separation mainly depending on the molecular weights are followed by the separation depending on the polarities. This geometry was more effective for the separation of the samples used in this study than the reversed one

Including typical procedures for heart-cutting described in experimental section, various modes of operations are feasible with this system, compared with the reports by Lee et al. [3,4]. Operations similar to those of a Dean's type pneumatic interface for GC-GC are feasible [5]. First, the separation on the primary column can be done without transferring solutes with the bypass valve switched to the bypass line 2. Second, the elution through both columns in series without fractionation can be done with the bypass valve closed, resulting in two chromatograms. Third, fractionations can be performed successively and discretely. Therefore, only the fractions of interest can be separated on the secondary column, leading to time saving. Furthermore, because of no unswept space in this system, direct injection of sample solution into the system, which results in a large solvent peak for the primary separation, does not disturb the baseline of the secondary separation.

\section{Comparison of elution methods and effects of resistance of transfer line}

Figure 4 shows a separation of the standard mixture on the primary column and a comparison of two elution methods for the secondary separation (refer to method-I and -II in experimental section). A fraction containing $\mathrm{C}_{16} \mathrm{Me}$ and $\mathrm{C}_{16} \mathrm{OH}$ was transferred to the secondary column. Separations (Figs. 4b and 4c) on the secondary column were done with method-II and method-I, respectively, using same setup. The resolution with method-I was higher, although analytical time was longer. It should be noted that the inlet pressure of the secondary column is lower for method-I than for method-II as shown in figure 3 , because the mobile phase is supplied through both the bypass line 1 and the transfer line for method-I while through the only bypass line 2 for method-II. Increasing resistance of the transfer line for method-I also increased the resolution at a expense of analytical time (Figs. 4c and 4d).

Obviously, the improved resolution can be attributed to the decreased pressure at the inlet of the secondary column. Later changes in retention can be expected for $\mathrm{C}_{18} \mathrm{OH}$ than $\mathrm{C}_{16} \mathrm{Me}$, because the secondary column is polar HP-WAX. The results indicates that selectivities in the separations on the secondary column can be tuned by changing the resistance of transfer line. In other words, pressure can be used

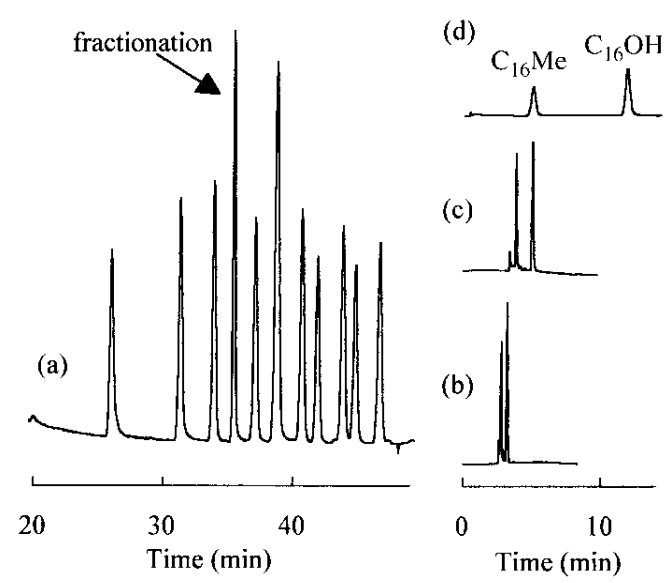

Figure 4. Two-dimensional SFC chromatograms of test sample showing a comparison of elution methods and the effect of resistance of transfer line. a) obtained by FID 1 without fractionation. b) obtained by FID 2 using elution method-II. c) and d) obtained by FID 2 using elution method-I. Primary column: HP-1. Secondary column: HP-WAX. Temperature: $100{ }^{\circ} \mathrm{C}$. Pressure: $100 \mathrm{~atm}$ for $10 \mathrm{~min}$ then programmed at $5 \mathrm{~atm} / \mathrm{min}$ to $300 \mathrm{~atm}$. Transfer line: c) $10 \mu \mathrm{m}$ i.d. $\times 10 \mathrm{~cm}$, d) $10 \mu \mathrm{m}$ i.d. $\times$ $20 \mathrm{~cm}$. Bypass line: $50 \mu \mathrm{m} \times 20 \mathrm{~cm}$.

as one of variables for tuning selectivities as in single column SFC. The transfer line may play a role of focusing solutes on the secondary column to some extent. In addition to pressure, temperature also affected the selectivities as in single column SFC [6-8]. Thus, two-dimensional SFC with the present interface can offer versatile methods for analyzing complex mixtures and closely related compounds. Detailed studies on selectivities will be reported elsewhere.

\section{Applications}

Figure 5a shows a separation of ethoxylate oligomers with two branches of polyoxyethylene on the primary HP-1 column. The oligomers seem to be eluted according to the molecular weight, i.e., number of oxyethylene (EO) units. Figures $5 \mathrm{~b}$ to $5 \mathrm{~d}$ show the separations of fractions $\mathrm{F} 1$ to F3 on the secondary HP-WAX column, where F1 and F2 were further separated into several peaks. Since the oligomers contain two branches of polyoxyethylene, even species with same number of EO units should include isomers with a different combination of EO units. These isomers may have different polarities, although their assignments were not studied at present.

Figure 6a shows a separation of a mixture of cholesterol and cholesteryl esters on the primary HP-1 column. F1 contained chol-16:0 and chol-16:1 of which fatty acid moieties have the same number of carbon atoms but different number of double bonds. F2 contained chol-18:0, chol-18:1, chol-18:2, chol-18:3 and chol-20:4. Components of each fraction were resolved on the secondary HP-WAX column (Figs. 6b and 6c). In this case, the cholesteryl esters were separated in the order of increasing number of double bonds (i.e., increasing polarities) as expected. 

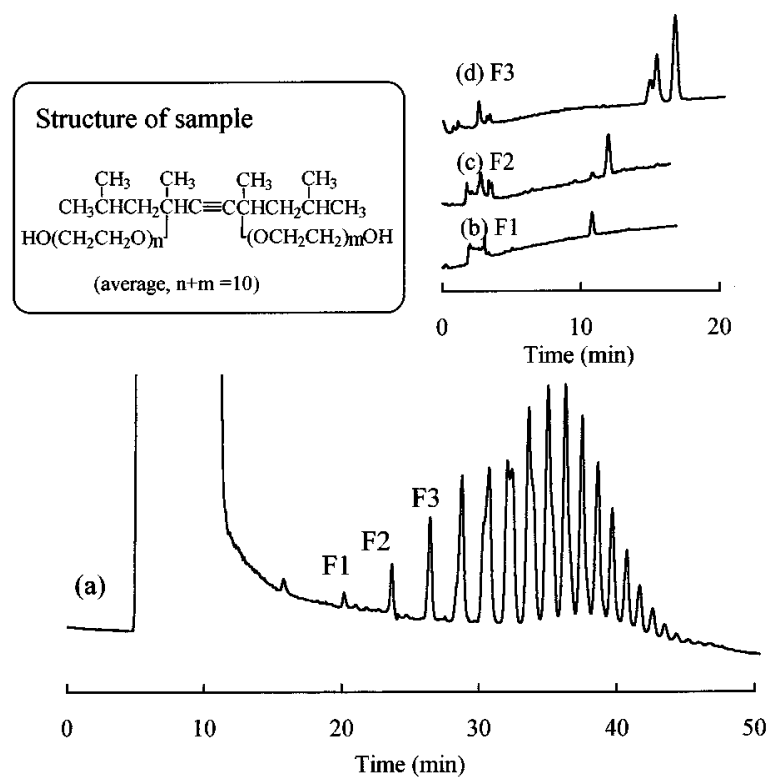

Figure 5. Two-dimensional SFC chromatograms of isomeric ethoxylate oligomers using elution method-I. a) obtained by FID 1 without fractionation. b) to d) obtained by FID 2 for fractions F1 to F3. Primary column: HP-1. Secondary column: HP-WAX. Temperature: $100^{\circ} \mathrm{C}$. Pressure: $100 \mathrm{~atm}$ for $10 \mathrm{~min}$ then programmed at $5 \mathrm{~atm} / \mathrm{min}$ to $300 \mathrm{~atm}$. Transfer line: $10 \mu \mathrm{m}$ i.d. $\times$ $20 \mathrm{~cm}$.

\section{Conclusion}

A simple flow switching interface for two-dimensional capillary SFC was developed. With this system, heart-cutting as well as selectivity tuning on the secondary column can be done easily. In addition, ordinary single column elution as well as coupled column elution are feasible without any change. Applications revealed the effectiveness of this technique for the analysis of closely related compounds. This system may be applied to complex mixtures such as biological and environmental samples.

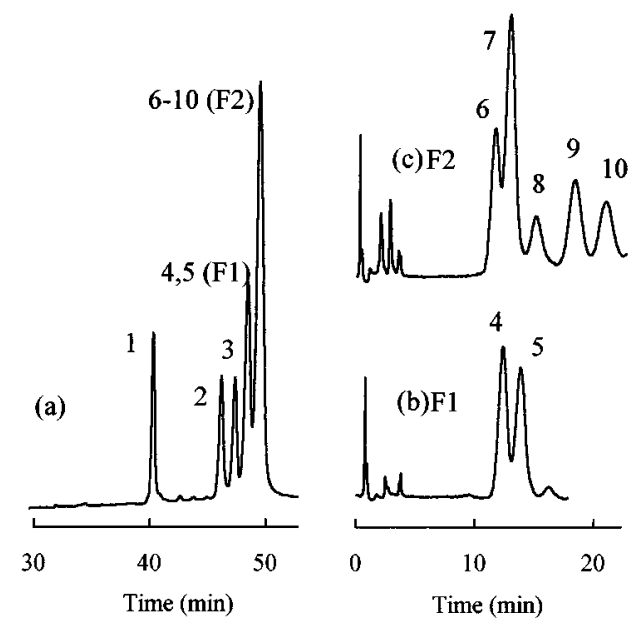

Figure 6. Two-dimensional SFC chromatograms of cholesterol and cholesteryl esters using elution method-I. a) obtained by FID 1 without fractionation. b) and c) obtained by FID 2 for fractions F1 and F2. Primary column: HP-1. Secondary column: HPWAX. Temperature: $115^{\circ} \mathrm{C}$. Pressure: $100 \mathrm{~atm}$ for $10 \mathrm{~min}$ then programmed at $5 \mathrm{~atm} / \mathrm{min}$ to $300 \mathrm{~atm}$. Transfer line: $10 \mu \mathrm{m}$ i.d. $\times 20 \mathrm{~cm}$. Peak identifications: $1=\mathrm{chol}, 2=\mathrm{chol}-\mathrm{C} 12: 0,3=\mathrm{chol}-$ C14:0, 4=chol-C16:0, 5=chol-C16:1, 6=chol-C18:0, 7=chol-C18:1, 8=chol-C18:2, 9=chol-C18:3, 10=chol-C20:4.

\section{References}

1. Davies, I. L.; Raynor, M. W.; Lithinji, J. P.; Bartle, K. D.; Williams, P. T.; Andrews, G. E. Anal. Chem. 1988, 60, 683A702A.

2. Bartle, K. D.; Davies, I. L.; Raynor, M. W.; Clifford, A. A.; Kithinji, J. P. J. Microcol. Sep. 1988, 1, 63-70.

3. Davies, I. L.; Xu, B.; Markides, K. E.; Bartle, K. D.; Lee, M. L. J. Microcol. Sep. 1989, 1, 71-84.

4. Xie, L. Q.; Markides, K. E.; Lee, M. L.; Hollenberg, N. K.; Williams G. H.; Graves, S. W. Chromatographia 1993, 35, 363-371.

5. Deans, D. R. Chromatographia 1968, 1, 18-22.

6. Wilsch, A.; Scheider, G. M. J. Chromatogr. 1986, 375, 239252.

7. Jones, B. A.; Shaw, T. J.; Clark, J. J. Microcol. Sep. 1992, 4, 215-220.

8. Chester, T. L.; Innis, D. P. J. Microcol. Sep. 1993, 5, 441-449. 